\title{
Cutaneous Melanoma TNM Finding v8
}

National Cancer Institute

\section{Source}

National Cancer Institute. Cutaneous Melanoma TNM Finding v8. NCI Thesaurus. Code C136892.

A finding about one or more characteristics of cutaneous melanoma, following the rules of the TNM AJCC v8 classification system. This classification system does not apply to melanoma of the conjunctiva, melanoma of the uvea, mucosal melanoma arising in the head and neck, and mucosal melanoma of the urethra, vagina, rectum, and anus. (from AJCC 8th Ed.) 